\title{
SEMIÓTICA E A TEORIA DA VISUALIZAÇÃO CARTOGRÁFICA: CONSIDERAÇÕES NA ANÁLISE DO PROJETO CARTOGRÁFICO
}

\author{
Semiotics and the Cartographic Visualization theory: considerations on the analysis \\ of map design \\ ESTEVÃO PASTORI GARBIN ${ }^{1}$ \\ FERNANDO LUIZ DE PAULA SANTIL ${ }^{2}$ \\ JOÃO VITOR MEZA BRAVO 3 \\ ${ }^{1}$ Universidade Estadual de Maringá \\ Departamento de Geografia \\ ${ }^{2}$ Curso de Pós-Graduação em Geografia \\ Av. Colombro, 5790 - Campus Universitário, Bloco J12 \\ 87020-900 - Maringá - Paraná - Brasil \\ ${ }^{3}$ Universidade Federal do Paraná \\ Setor Ciências da Terra - Departamento de Geomática \\ Curso de Pós-Graduação em Ciências Geodésicas \\ 81.531- 990 -Jardim das Américas - Curitiba- PR \\ estevoepg@gmail.com; flpsantil@uem.br; jvmbravo@gmail.com
}

\section{RESUMO}

Este artigo tem como objetivo refletir sobre as discussões contemporâneas advindas da teoria da visualização cartográfica, com ênfase na elaboração dos signos gráficos utilizados em mapas analógicos. Para tanto, buscamos fazer apontamentos sobre as etapas no desenvolvimento do projeto cartográfico, valendo-nos, sobretudo, de parâmetros da semiótica de extração peirceana. Por intermédio da aplicação da leitura semiótica em mapas topográficos e sinóticos apresentaremos as particularidades das estratégias de cada produto, a fim de se mostrar uma alternativa aos autores de mapa para a elaboração de signos gráficos mais eficazes para cada tipo de usuário. Compararemos, também, as perspectivas existentes sobre as teorias do conhecimento, apontando novas questões a serem pensadas sobre o processo de construção da informação espacial adquirida dos mapas.

Palavras-chave: Projeto Cartográfico; Visualização Cartográfica; Semiótica. 
This paper aims at composing a reflexive approach of contemporary discussions, arising from the theory of cartographic visualization, with emphasis on the issues of construction of signs used in paper maps. To make it, we tried to combine the MacEachren (1994a \& 1995) and Slocum (1999) discussions about map design steps; specially those linked with the Peirce semiotic extraction parameters. Through the application of semiotic reading of topographic and synoptic maps, the particular issues related to the strategies of each cartographic product studied will be shown in order to present an alternative way to map makers in the tasks of construction of more effective signs to different kind of map users. There will be comparison between the perspectives related to the theories of knowledge pointing at new issues in the way of the process of construction of spatial information through maps.

Keywords: Map Design; Cartographic Visualization; Semiotics.

\section{INTRODUÇÃO}

Elaborar um projeto cartográfico é uma tarefa extremamente complexa. Através dele, o autor transportará uma realidade viva, dinâmica e rica para um plano estático, imóvel e silencioso. Naturalmente, questões relacionadas a seleção e a codificação das informações deverão ser minuciosamente trabalhadas pelo seu autor, face aos objetivos pretendidos e, também, às características do leitor que decodificará posteriormente o mapa.

Desta forma, um mapa é um elo de ligação entre dois leitores do espaço: o autor, com suas impressões através de uma representação; e o usuário de mapas, que interpretará as informações recebidas da carta de acordo com um repertório próprio de conceitos mentais. Esta concepção de Kolácný, como aponta Sluter (2008), foi um marco em demonstrar que a transposição da realidade percebida pelo cartógrafo ao plano deve ser refletida em todos os aspectos existentes entre o ser humano, o mapa e o espaço. Em tempo: esta relação não é linear, sistemática ou mesmo claramente compreendida.

Embora a formulação do projeto cartográfico direcione, obviamente, à cartografia, as discussões que envolvem as variáveis a serem consideradas para sua elaboração ainda não são consensuais. Isto se dá pela transversalidade dos conhecimentos exigidos pelo cartógrafo na concepção de seus produtos: não se busca somente representar algo, mas tornar esta representação legível e passível de exploração por um terceiro.

A psicologia, as ciências da comunicação e a informática contribuíram para as discussões sobre os processos cognitivos executados pelo usuário ao ler um mapa, principalmente a partir da segunda metade do século XX. Como aponta Keates (1982), estas dificuldades não tratam somente da incapacidade dos cartógrafos em codificar informações espaciais de maneira legível, mas também da eficácia em se deduzir um conjunto de regras para um aprimoramento da leitura dos mapas. 
Sobre esses entraves, destaca Santil (2008, p.55):

Assim como há dificuldades em criar o mapa, as tarefas relacionadas à interpretação do mapa podem ser igualmente descritas. Questões relacionadas à cultura, diferenças entre os sexos, idade, ser especialista ou não especialista interferem nas habilidades cognitivas de recordar, de armazenar, entre outras, que podem afetar tanto tarefas simples, como a comparação de símbolos, como as de maior complexidade, que envolvam inferências sobre as relações entre os símbolos (SCOTT e BOARD, 1991, p. 211-215).

Sobre as necessidades de se repensar os papéis e métodos da cartografia convencional (realizada em meios analógicos ou com signos definidos em convenções), como as que tratam de mapas digitais, MacEachren (1994a) apresenta o modelo Cartografia ${ }^{3}$, que compreende não só a dimensão comunicativa do mapa, mas também sua função em se tornar objeto para a visualização. A visualização cartográfica, nesse sentido, se dá pela atribuição de novas possibilidades de se explorar informações de um produto cartográfico, por intermédio da formulação e confirmação de hipóteses sobre um mesmo mapa. Utilizada principalmente por um pequeno grupo de especialistas, a visualização torna possível ampliar o uso do mapa pela conjugação de três fatores: tipo de usuário (público ou privado - não especialista e especialista, respectivamente), interatividade (alta ou baixa) e seu papel em apresentar o conhecido ou explorar o desconhecido (MACEACHREN, 1994a), como ilustra a Figura 1.

Figura 1 - Modelo (CARTOGRAFIA) ${ }^{3}$ de MacEachren (1994a). Fonte: Adaptado de MacEachren (1994a, p. 5).

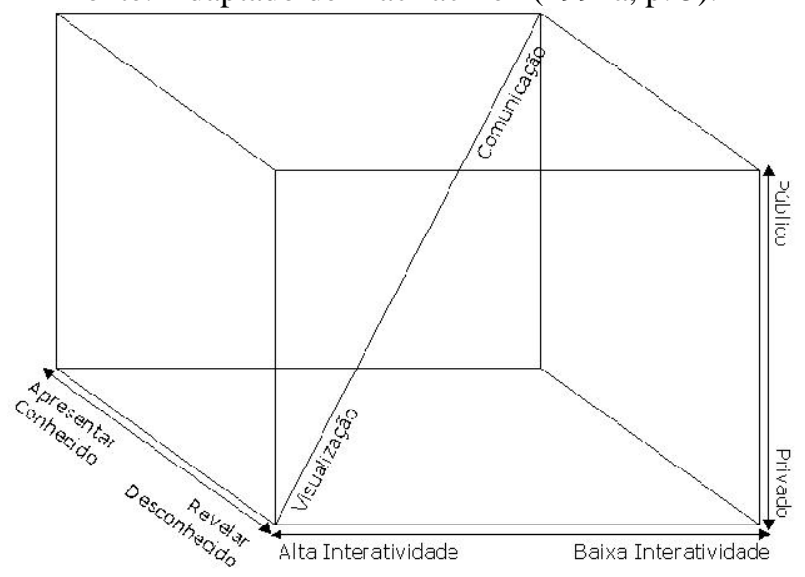

Bol. Ciênc. Geod., sec. Artigos, Curitiba, v. 18, nº 4, p.624-642, out-dez, 2012. 
Vale ressaltar que, apesar do importante papel dos computadores no exercício de repensar cartografia, sua presença não é decisiva nas discussões sobre a visualização. A interação destacada por MacEachren (1994b, p.5) é relativa aos tipos de usos potencialmente permitidos pelo mapa, dos quais a comunicação configura-se como um subcomponente da visualização e não somente a interação promovida exclusivamente pelos meios digitais.

Embora o termo visualização seja recente na literatura cartográfica, a variável interatividade é antiga. As Grandes Navegações, por exemplo, foram eventos que, além de contar com o saberes-fazeres dos navegantes, necessitaram do auxílio do mapa como ferramenta de exploração e não somente apresentação das rotas conhecidas. Apesar das ferramentas computacionais facilitarem a manipulação e a adaptação do produto cartográfico, o meio analógico historicamente possibilitou a pluralidade funcional do mapa e ainda hoje seus autores são responsabilizados para resolverem os diversos problemas da relação mapa-usuário.

Ainda com o advento das técnicas de impressão de alta qualidade, que promoveram maior liberdade na concepção de signos mais minuciosos para os leitores, os problemas semânticos relativos à decodificação pouco apontam para uma solução definitiva. A criação de um produto cartográfico que possibilite a plena comunicação depende de uma gama de fatores, muitos ainda desconhecidos. $\mathrm{O}$ papel da subjetividade em influenciar a categorização de conceitos adquiridos ou adaptados, por exemplo, leva aos pesquisadores desafios distantes de uma compreensão clara do fenômeno.

Sobre a elaboração do projeto cartográfico, Slocum (1999, p.5-6) apresenta dez etapas, abrangendo desde os objetivos que serão alcançados por aqueles que o utilizarão, o tipo de público, até o projeto dos signos gráficos utilizados na representação. A etapa para a elaboração dos signos que compõem o produto cartográfico não deve ser considerada independente das demais, pelo contrário: os signos gráficos devem estar pautados no perfil do usuário bem como seus objetivos, qualquer que seja a natureza do produto. Principalmente quando se trata de mapas temáticos, a elaboração do conjunto de signos mostra-se uma tarefa difícil, tendo em vista a ausência de convencionalidade das formas (SLUTER, 2008, p.9). Mesmo em mapas convencionados, os aspectos dos signos na maioria das vezes não favorecem sua interpretação: a carta topográfica é exemplo da falta de preparo deste tipo de documento para com a leitura do usuário. Isso se configura como um problema relevante, uma vez que são produtos que devem servir de base para diversas tarefas que exijam representação ou interpretação de fenômenos espaciais.

Considerando-se que as tentativas iniciais em se cartografar o mundo ainda influenciam os produtos cartográficos vigentes, como testemunham as cartas sinóticas e mesmo as cartas de uso do solo dos séculos XVIII e XIX , cria-se uma demanda de novas análises mais fecundas para o resolução de certos impasses, principalmente de natureza semântica. Nesse sentido, a perspectiva que a cartografia assumiu nas últimas décadas, relacionadas à incorporação de métodos e técnicas computacionais à representação espacial e inter-relação de dados, está pautada em 
teorias pouco discutidas e avaliadas nessa área do conhecimento. A Semiologia Gráfica de Bertin, por exemplo, é um caso muito presente entre a comunidade acadêmica, porém alguns questionamentos fundamentais quanto à estruturação de seus princípios carecem de respostas, como será abordado neste trabalho a posteriori, ainda que alguns métodos para se testar esses produtos e sua eficácia quanto à comunicação com os usuários tenham sido construídas, como é o caso de Nivalla (2007) e Mendonça \& Delazari (2012).

Neste sentido, este trabalho tem como objetivo discutir o projeto dos signos gráficos utilizados em mapas, refletindo sobre os entraves e as possibilidades para maximizar a eficácia de sua visualização. Para tanto, utilizaram-se as discussões referentes à semiótica peirceana para o direcionamento de questões pertinentes ao autor do mapa e sua técnica de elaboração, relacionando as concepções modernas a respeito do processo de categorização mental. Buscou-se em Keates (1982) reflexões acerca das implicações dos usos de signos gráficos nos mapas, conjugados com a perspectiva das teorias do conhecimento contemporâneas apontadas por Lakoff (1987).

\section{AS CONCEPÇÕES SEMIÓTICAS E SEUS REFLEXOS NA CARTOGRAFIA}

A cartografia é uma ciência capaz de reproduzir as informações de parte da realidade em diferentes escalas, porém torna-se demasiadamente complexa quando há generalização dos elementos a serem representados. A semiótica compartilha de teorias que ajudam a compreender a realidade e, talvez, o potencial indagativo desta realidade complexa. Nesse contexto a semiótica tem um importante papel: compreender e analisar o poder de comunicação dos mapas. Assim, pesquisas voltadas à semiótica na cartografia são de grande valia no que se refere aos processos de criação e uso dos produtos cartográficos.

Apesar das discussões históricas sobre a relação entre os signos e seus efeitos, cujos vestígios estão ligados a Platão e Hegel, somente na segunda metade do século XX a cartografia se valeu das concepções semióticas modernas para a discussão do projeto cartográfico. Foi Bertin (1983) que inaugurou uma nova fase na cartografia: a busca da maneira mais adequada em se representar as informações, cujas propriedades específicas originaram as variáveis visuais. Suas considerações estão pautadas nas concepções estruturalistas de Ferdinand de Saussure, um dos principais autores da semiologia geral e da linguística moderna (QUEIROZ, 2000, p.121).

Para Bertin, a linguagem cartográfica é composta por signos gráficos, cuja estruturação se dá pela presença de dois elementos: o significante e o significado. Significante, nesta perspectiva, é a forma com que uma determinada informação se materializa para que seja passível de leitura. No caso dos mapas, estes significantes são os signos gráficos que representam uma determinada informação espacial - o significado.

Apesar da linearidade e arbitrariedade dos signos defendidas por Saussure, Bertin (1978) indicava que a linguagem cartográfica deveria ser monossêmica e não 
convencionada. De acordo com Queiroz (2000, p.121-122), Bertin apontou que a cartografia, por ser uma linguagem universal, deveria propor um sistema de signos que tornassem sua leitura eficaz para qualquer tipo de usuário.

Sobre as regras lógicas utilizadas por Bertin, Queiroz (2000, p.122) afirma que:

\begin{abstract}
Bertin identifica três relações - similaridade, ordem e proporcionalidade -, que consistem nos significados da representação gráfica, e são expressas pelas variáveis visuais - tamanho, valor, textura, cor, orientação e forma - , que são os significantes. Essas variáveis visuais têm ainda três modos de implantação, a saber: o linear, o pontual e o zonal.
\end{abstract}

Este conjunto de saberes desenvolvido pela Semiologia Gráfica de Bertin é muito difundido pelos cartógrafos na elaboração de mapas temáticos. Entretanto, o advento de outras correntes da semiótica e outras ciências, principalmente a partir da segunda metade do século $\mathrm{XX}$, trouxeram novos horizontes às discussões da elaboração dos signos gráficos, mas que também afetam a própria forma de pensar o projeto cartográfico.

A psicologia, por meio dos estudos na ciência cognitiva (LURIA, 1976) e das teorias do conhecimento (ROSCH, 1973), por exemplo, é uma das áreas que contribui para os avanços nas pesquisas em cartografia, estudando os processos mentais que comandam as ações humanas na criação e na leitura de produtos cartográficos. O raciocínio espacial é o objeto de estudo da cartografia e as evidências advindas da ciência cognitiva no tocante à percepção humana auxiliam na geração de mapas adequados ao seu público (MACEACHREN, 1995). Por outro lado, a semiótica quando interligada à essência do conhecimento em toda sua diversidade, faz com que surjam discussões capazes de sanar algumas "deficiências epistemológicas” dessas outras áreas do conhecimento. Este fato é destacado por Paschoale (1989, p.8), que buscou conceitos da semiótica para a Geologia. Este autor destaca o crescimento de outras ciências quando estas buscam trazer ao viés de formação de seus profissionais a filosofia da ciência e a semiótica, e cita que "a biologia, nas últimas décadas, procurou romper este circuito fechado. Basta lembrarmos das contribuições de Piaget ou de Monod para darmos conta das verdadeiras revoluções na Epistemologia que ocorreram com seus trabalhos”.

MacEachren (1995) inicia um estudo muito semelhante na cartografia e discute algumas teorias em relação aos processos de elaboração e leitura de mapas. Aborda e expõe suas posições frente à diversidade de teorias da função comunicativa dos mapas. Seus estudos abrem caminho para discutir conceitos referentes à semiótica e trazer uma relação entre a cartografia, a comunicação e a visualização espacial.

Nesse sentido, a compreensão e as propostas para esquematizar as teorias do conhecimento fortaleceram algumas correntes de pensamento semióticos, como as de Peirce. Segundo Nöth (2003, p.13), a semiótica não se limita somente ao estudo 
dos signos linguísticos, mas também aos signos presentes na natureza. Signo, nesta perspectiva, é tudo aquilo que "dá corpo às emoções, ao pensamento, reações etc." (SANTAELLA, 1983 p.10), tendo sua existência na mente do receptor e não no mundo exterior. Assim, a semiótica possibilita entender os mecanismos utilizados por aqueles que produzem tais signos, compreendendo suas estratégias para que a informação seja transferida da maneira pretendida.

Se o signo de Saussure, adotado por Bertin, é composto por apenas dois elementos, o signo para Peirce é composto por uma tríade indissolúvel. O elemento ímpar da noção peirceana é o objeto, aquilo que se pretendeu representar, mas que não fora, necessariamente, alcançado em sua plenitude.

Considerando os conceitos de Peirce para a cartografia, o signo peirceano é composto por um objeto - chamado de referente por MacEachren (1995) - que é aquilo que se busca representar, o qual assume uma forma através de um representamen (veículo sígnico), que para a cartografia é o símbolo cartográfico. Erroneamente isso é chamado símbolo, posto que esta é uma classificação de uma relação especial entre o representamen e o objeto por meio de uma lei. O terceiro elemento desta tríade é o interpretante, na semiótica peirceana, ou significado para semiologia saussuriana, que constitui os efeitos causados pelo signo na mente do receptor, ou seja, a associação de ideias realizadas pelo usuário.

Ao processo de atribuição de significados a um significante é conferido o nome de semiose, que potencialmente se torna ilimitada, considerando-se as infinitas possibilidades de reordenar ou recriar este processo. Trata-se de um processo de revelação individual, ou seja, intrínseco a cada ser humano. Assim sendo, traz consigo a possibilidade de engano interpretativo. Na cartografia é muito comum a ocorrência deste fato que acontece por conta das diferenças sensoriais e cognitivas de cada sujeito.

A semiótica de Peirce inclui, também, categorias universais para os signos. Se os primeiros pensadores da semiótica criaram dezenas de categorias para acolher os diversos elementos presentes em nosso universo, tal como Aristóteles, que formulou dez, ou Hegel, que formulou doze, Peirce sintetizou todos os signos em apenas três categorias. A maneira com que elas se diferenciam se dá pela forma com que os fenômenos se apresentam à mente (NÖTH, 2003).

A categoria da primeiridade envolve todos os fenômenos que ainda não são estruturados suficientemente para serem signos. Para Nöth (2003, p.63), “é a categoria do sentimento imediato e presente das coisas, sem relação com nenhum outro fenômeno do mundo", e, por isso, está inteiramente presente no campo das possibilidades, daquilo que pode vir a ser. Já a categoria da secundidade na natureza configura como o aqui-agora, a "matéria enquanto presentificação", atualidade (PASCHOALE, 1989, p.51). Por fim, a terceiridade que "é a categoria que relaciona um fenômeno segundo a um terceiro” (NÖTH, 2003, p.64), seja mediando, promovendo uma continuidade ou representando outro signo. Desta forma, os fenômenos que são locados nas categorias da primeiridade e secundidade não são 
passíveis de explicação. Simplesmente são (PEIRCE: 1.405 apud PASCHOALE, 1989, p.52).

Além destas categorias e dos elementos do signo, o sistema semiótico de Peirce engloba, também, a relação que pode existir entre seus três elementos constituintes em três categoriais distintas. As principais combinações são apresentadas no Quadro 1.

Quadro 1 - combinações possíveis entre os constituintes e as categorias do signo Fonte: Adaptado de Nöth (2003, p.90).

\begin{tabular}{|l|l|l|l|}
\hline TRICOTOMIAS & I & $\begin{array}{l}\text { II } \\
\text { Representamen } \\
\text { Objeto }\end{array}$ & $\begin{array}{l}\text { III } \\
\text { Representamen } \\
\text { Representamen }\end{array}$ \\
\hline Primeiridade & Quali-signo & Ícone & Rema \\
\hline Secundidade & Sin-signo & Índice & Dicente \\
\hline Terceiridade & Legi-signo & Símbolo & Argumento \\
\hline
\end{tabular}

Da relação existente entre o representamen com ele mesmo, na categoria da primeiridade, temos o quali-signo. Segundo Nöth (2003, p.76) quali-signo é uma qualidade que é um signo, não atuando diretamente como signo, posta a necessidade de uma corporificação para chegar ao mundo disponível à apropriação. Na categoria da secundidade esta relação origina os sin-signos, que são os signos que possuem um significado, como a concepção de legenda, por exemplo. No domínio da terceiridade temos os legi-signos, que são originados por intermédio da ação de uma lei que socialmente determina seu significado.

Sobre as relações possíveis entre o representamen e o objeto - que para MacEachren (1995, p.222) são as categorias mais importantes para os semioticistas e cartógrafos - encontram-se o ícone, o índice e o símbolo. O ícone, que ocorre no domínio da primeiridade, é constituído pela indução de semelhanças entre o objeto e seu representamen, fundamentados por um quali-signo (SANTAELLA, 2004, p.17). Assim, por estarem conectados somente pelas semelhanças, o ícone é um tipo de signo com rápida interpretação. Uma fotografia de uma pessoa, por exemplo, é o seu ícone.

O índice é o resultado da leitura de um fenômeno pelos seus atributos mais periféricos: por exemplo, o barulho de um trovão pode indicar chuva. Não se trata da água da chuva caindo, mas sim o barulho relativo a uma tempestade, que está diretamente ligada à ideia de chuva, ou seja, o trovão é um índice de outro signo, a precipitação pluvial. Ele se encontra na categoria da secundidade.

O símbolo, por fim, está ligado à categoria da terceiridade. As convenções sociais e culturais são as responsáveis pela elaboração dos símbolos, que são resultados de uma conexão compartilhada do representamen com seu objeto. Entretanto, para um símbolo ser passível de uma interpretação adequada, é necessário que o interpretador do signo conheça os códigos vigentes. Uma carta topográfica, por exemplo, é repleta de símbolos convencionados. Esta convenção, apesar de buscar uma universalidade da significação do signo, restringe a 
quantidade de usuários que poderão se valer dessa carta para sua exploração; talvez aqueles que aprenderam a decifrar o seu código possam lê-la e, consequentemente, interpretá-la.

A palavra símbolo é em muito difundida pelos cartógrafos para a designação dos signos gráficos presentes nos mapas. Essa palavra, no entanto, não é muito coerente ao expressar sua relação estruturada na semiótica peirceana, cujos princípios condicionantes foram generalizados, como aponta MacEachren (1995, p.218). Assim, falar em simbologia seria tratar do estudo dos símbolos. Apesar de os mapas convencionados terem a presença de diversos símbolos, os mesmos não são absolutos, estando presentes também ícones e índices, os quais estão subordinados à semiótica.

Na visão de MacEachren (1995), essas entidades relacionais ligadas à forma de interpretação descrevem níveis hierárquicos, os quais ele reinterpreta e traz para a cartografia com a denominação de taxonomia e partonomia. A taxonomia está ligada à interpretação de elementos e o relacionamento entre estes de forma complexa, utilizando-se da cognição; e a partonomia, ligada a elementos da percepção para interpretação da mensagem.

Quanto à relação entre o representamen com o interpretante, as combinações mais utilizadas se dão pela rema, o dicente e o argumento. Por não estarem evidenciadas nesta discussão, suas definições poderão ser encontradas em outros trabalhos, como os de Nöth (2003) e Santaella $(1983,2004)$.

Esta rápida lembrança das principais combinações possíveis entre os signos em suas diversas categorias ilustra a riqueza da teoria peirceana. Sua complexidade, inclusive, é um dos grandes fatores de entrave para sua disseminação entre os cartógrafos.

\section{A PERSPECTIVA SEMIÓTICA DA LEITURA DE MAPAS}

A perspectiva da semiótica de Peirce adiciona horizontes mais amplos se comparada a de Bertin para elaboração de signos em um mapa. Se para Bertin a linguagem cartográfica deve ser monossêmica, Peirce aponta que esse caminho para a unilateralidade é quase impossível de se concretizar. A presença do elemento objeto no signo considera que a intenção daquilo que se pretende representar não é necessariamente aquilo que se representou. Isto aumenta ainda mais a responsabilidade do autor de mapas em projetar os signos cartográficos: se, por exemplo, o representamen (sinal gráfico no mapa) busca representar um tipo específico de vegetação (objeto), então, o cartógrafo deverá se valer de sua gama de conhecimentos sobre o objeto e sobre o tipo de leitor que utilizará sua carta, para que seu representamen atinja o interpretante esperado.

Sobre estas possíveis discussões permitidas pelo modelo triádico do signo, MacEachren (1995, p.219) é enfático ao afirmar que:

$$
\begin{aligned}
& \text { O modelo diádico do signo saussureano explicitamente omite } \\
& \text { o referente (objeto). Para Saussure, a semiologia (i.e. }
\end{aligned}
$$


semiótica) opera com um sistema de signos completamente arbitrário, que nada explica sobre como os veículos-sígnicos (representamen) se referem às entidades do mundo real, mas apenas como se referem aos conceitos mentais (tradução nossa).

As diferenças entre as concepções saussureanas e peirceanas sobre os signos são extremamente complexas, como se nota. Desta forma, Santaella (1983) aponta que estas diferenças são tão fundamentais que são praticamente separadas pela trajetória inversa do desenvolvimento destas teorias. Para Saussure, sua linguística surgiu do corte mais abrupto da linguagem com todos os processos cognitivos, as influências culturais e todas as ciências. Para Peirce, entretanto, sua semiótica está diretamente ligada a toda a gama de fatores que envolvem o pensamento, inclusive a linguagem, já que a teoria de Peirce é uma teoria sígnica do próprio conhecimento (SANTAELLA, 1983).

Considerando os processos orgânicos à discussão de como o conhecimento é estruturado, as discussões relativas à teoria da visualização cartográfica identificamse em sua problemática com a semiótica de Peirce, que abrange questões internas e externas do interpretador, seja de mapas ou mesmo do próprio mundo. Além disso, Bertin buscou permitir que os mapas fossem lidos basicamente com a ação da percepção, em um curtíssimo espaço de tempo, o que torna mais difícil o papel de explorador do usuário de mapas na busca de hipóteses não evidenciadas em uma representação.

Tais questionamentos tornam-se mais visíveis quando se considera que a teoria de Bertin foi elaborada considerando isoladamente a percepção das variáveis visuais e não as discutiu em relação ao processo cognitivo entre o emissor e receptor (SANTIL, 2008, p.55). Este autor destaca ainda que:

\begin{abstract}
Autores como Morrison (1974), Caivano (1990) e MacEachren (1995) propuseram a inclusão de novas variáveis visuais às apresentadas por Bertin; reforçando inclusive, do ponto de vista semiótico, estudos quanto às combinações dos signos (sintática), das relações com os objetos representados (semântica) e dos efeitos dos signos nas pessoas que os usam (pragmática) (grifo nosso).
\end{abstract}

Estas relações buscadas pelos cartógrafos, que admitem a não linearidade do pensamento e que consideram a nebulosidade do processo de categorização das informações pelo leitor de mapas, refletem as novas teorias do conhecimento estruturadas pós-década de 1950.

Lakoff (1987), em suas discussões sobre o processo de desenvolvimento de categorias e como se dá o processo de categorização, aponta duas principais correntes teóricas. A primogênita, conhecida como teoria clássica da categorização, sugere que as categorias são grupos naturais à disposição na natureza para serem 
encontrados. Todos os elementos que compõem uma mesma categoria compartilham os mesmos atributos, tendo sua representatividade igual a qualquer outro integrante.

Entretanto, a falta de empirismo destas condições tornou essa teoria insuficiente mediante as novas proposições advindas nos anos pós década de 1960 . Em seu resgate histórico, Lakoff (1987, p.16-57) aponta o desenvolvimento de uma nova perspectiva para a compreensão do processo de categorização dos signos, tendo sua síntese originada pelas discussões de Rosch (1975).

De acordo com a teoria do protótipo, cada categoria é fruto de relações altamente individuais, que refletem toda a construção cultural, social, econômica e fisiológica do usuário. Além disso, as categorias são estruturadas por um membro central, que compartilham as características mais ilustrativas daqueles que serão pertencentes às categorias. Os limites destas não são facilmente definidos, mas nebulosos. Desta forma, a maneira com que um estímulo é compreendido por um usuário depende de uma importante gama de fatores, inclusive o próprio contexto no qual o estímulo é apresentado (ROSCH, 1975).

Em consonância com estes apontamentos, mesmo antes de serem difundidos, Brown (1958) discute as relações entre as categorias existentes entre o universo de um adulto e de uma criança. Para o autor, as categorias subordinadas compreendem os objetos que criam relações mais diretas entre a criança e o objeto. Simplificando essa condição, o autor utiliza como exemplo o caso do leite e da água, reconhecidos anteriormente à categoria líquido (BROWN, 1958, p.17-18). Portanto, ao passo em que se procura desenvolver raciocínios mais elaborados, trabalhando com categorias mais superordenadas no usuário de mapas, é necessário que o leitor tenha os prérequisitos já internalizados. Antes de se desenvolver as categorias mais abstratas, o usuário deverá ter desenvolvido aquelas mais concretas (BROWN, 1958, p.20).

Para o autor de mapas que deseja elaborar um produto passível de exploração, o mesmo deve possibilitar que diversos níveis de categorias (superordenadas e subordinadas) sejam interpretadas, tendo o grau de sua interpretação variável de acordo com o perfil de seu leitor, seja ele especialista ou não. Desta forma, quando se considera os princípios de Peirce sobre o processo de semiose, ou seja, a atribuição de um interpretante ao representamen, é correto afirmar que tal processo não é linear, natural ou controlável. Apesar das ações já compreendias pela Gestalt sobre os efeitos que alguns estímulos causam em nosso processo perceptivo e cognitivo, a atribuição de significados mais elaborados e que necessitam de categorias superordenadas (abstratas) por parte de seu interpretador não depende somente do estímulo gerado, mas sim do perfil de cada observador.

Pode-se considerar essa variável como um ponto negativo para a concepção semiótica do processo de leitura de mapas. Entretanto, uma das doutrinas inerentes à semiótica de Peirce é a da falibilidade. Para Paschoale (1989, p.45), a doutrina do falibilismo de Peirce pode ser definida como: 
A impossibilidade de se ter certeza ou universalidade a respeito de questões de fato (1.149), através do raciocínio; e não sendo possível através do raciocínio, a certeza absoluta sobre questões de fato não pode ser alcançada por nenhum outro processo (1.142). Mesmo a experiência direta não proporciona esta certeza, pois esta não é nem certa nem incerta, apenas é (1.145).

Assim, quando o cartógrafo busca elaborar signos fidedignos para seus mapas, deverá considerar que sua concepção sobre o que se busca representar não reflete a realidade pura, mas seus conceitos sobre ela (MACEACHREN, 1995, p.220). Portanto, o cartógrafo deve se atentar aos critérios utilizados na abordagem do fenômeno a ser representado, porque sua própria concepção do objeto está filtrada em ao menos três níveis: sensorial, funcional e cultural (Santil (2008, p.83-84)):

[o filtro] sensorial diz respeito às respostas sensoriais, exemplo, os daltônicos não vêem certas cores. O funcional ou operativo faz menção às características psicofisiológicas constitutivas do receptor, isto é, ao se ler uma mensagem essa será executada diferentemente por um adulto e por uma criança, porque possuem diferenças em suas estratégias mentais. Em relação ao cultural, apenas as mensagens que fazem parte do universo cultural do indivíduo serão capturados.

Neste sentido, o processo que leva o usuário ao encontro do objeto buscado pelo cartógrafo é interpretado em dois níveis. O primeiro se dá pelo contato à feição mais imediata do objeto: a representação pictórica de uma árvore, por exemplo, resultará em um interpretante que corresponde à concepção geral de árvore. A busca pelo objeto imediato pode ser mais simples a ser alcançada quando trabalha com os critérios de categorização mais generalistas (partonomia).

Entretanto, no segundo nível, pela ação da cognição, essa mesma árvore poderá se reportar a uma espécie específica, ou indicar o grau de conforto térmico de um ambiente, por exemplo. Assim, o objeto imediato resultará no encontro de um objeto dinâmico, que transcende a generalização despertada e compartilhada a níveis muito dependentes do perfil do usuário (SANTAELLA, 2004, p.15) podendo, inclusive, se desviar do objetivo buscado pelo cartógrafo (taxonomia).

\section{ESTRATÉGIAS PARA O ALCANCE DO REPRESENTAMEN ALMEJADO}

Sobre as etapas para a elaboração de um projeto cartográfico, Sluter (2008, p.8) aponta que a primeira consiste em definir qual tipo de usuário utilizará o mapa e quais seus objetivos. Se o projeto cartográfico fosse um caminho a seguir, essa primeira etapa seria uma bifurcação que tornariam distintos os pontos de chegada: 
para o usuário especialista, os signos gráficos deverão ser pensados para atingirem fins diferentes daqueles cujos conhecimentos sobre o tema são pouco aprofundados.

Para ilustrar estas condições, a Figura 2 apresenta o modelo de DiBiase (1990 apud MacEachren 1994b, p.3) sobre as funções do mapa.

Figura 2 - Os tipos de uso e públicos de um mapa.

Fonte: Adaptado de MacEachren (1994b, p.2).

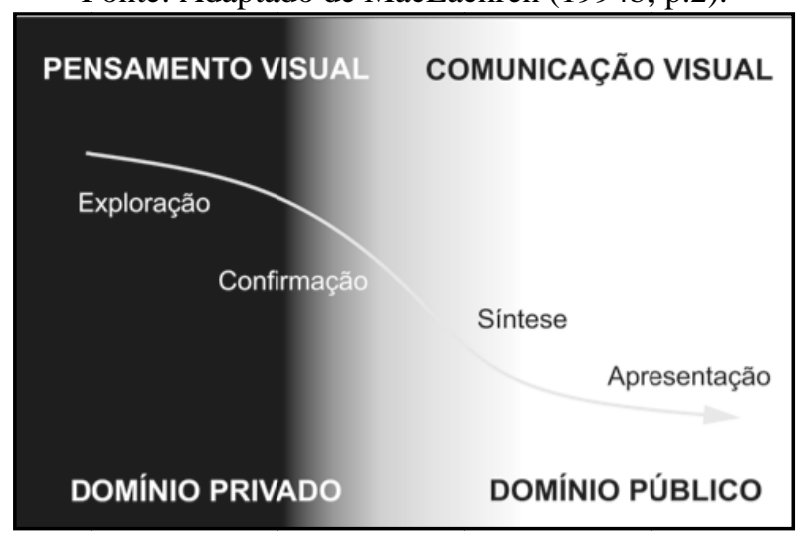

Através dessa representação, é possível observar que tipos diferentes de usuários farão usos distintos do mapa. O domínio privado, por exemplo, é marcado pela atuação de leitores especialistas, cuja exploração e confirmação de informação envolverão processos mais elaborados do que aqueles que somente buscam sínteses e apresentações de informações em um mapa. Isso significa que o usuário especialista terá que recorrer a processos de categorização mais complexos que os não especialistas - do ponto de vista do rigor científico ao interagir com o produto cartográfico a fim de explorá-lo. Assim, as categorias dos objetos dos usuários especialistas terão que ser estruturadas através da racionalização científica, mais complexa e com diversos elementos prototípicos.

Esses quatro processos são extremamente dinâmicos e dificilmente ocorrem isoladamente. Entretanto, considerá-los é admitir que um produto assume funções mais apropriadas para um determinado grupo de usuários influenciando, assim, na forma de se conceber os signos utilizados no mapa.

Com relação à transição de variação dos tons claros e escuros observada na Figura 2, indica-se a incerteza em se definir os limites dos domínios de uso. Além disso, o autor não utiliza as extremidades nem o ponto médio para indicar os processos. Talvez este seja um indicativo da incerteza que deve guiar o cartógrafo na leitura dos processos que envolvem a interpretação de um mapa, tornando suas relações ainda mais complexas.

Por exemplo, a representação da topografia de uma região deve se efetuar pelo autor de formas distintas para esses dois grupos. Para o primeiro grupo, marcado 
pelos especialistas que buscarão novas hipóteses e confirmação de seus raciocínios, o mapa deverá conter atributos que possibilitem essa interação das diversas variáveis que envolvem o modelado do relevo, para assim favorecer a visualização (MACEACHREN, 1994b, p.2). Quanto ao segundo grupo, o mapa deverá conter uma síntese de todas as informações pertinentes aos seus usuários, cuja elaboração do projeto dos signos será pautada pela apresentação de algo que seja minimamente comum ao público não especialista, favorecendo a comunicação cartográfica de alcance mais amplo.

Nestas discussões, a semiótica peirceana pode adequar tais representações para esses dois grupos com diferentes soluções. Considerando as etapas da análise semiótica apresentadas por Santaella (2004), é necessário analisar como esses dois fenômenos podem se revelar para esses dois grupos.

Para o grupo de especialistas, a topografia é um aspecto do espaço geográfico que sintetiza diversas condições, tanto espaciais quanto temporais. Ela é um produto da ação de agentes internos alterados pela ação dos agentes externos. Assim, tipos específicos de rochas sob um determinado clima apresentarão feições específicas, pelo menos em um determinado recorte temporal.

Entretanto, a topografia envolve não somente os aspectos físicos de um ambiente, mas também humanos. Ela pode influenciar no modo de vida das pessoas, no tipo de construções que se adaptam ao ambiente e que, em condições socioeconômicas desfavoráveis, podem potencializar problemas ambientais que afetarão a qualidade de vida e a segurança dos seus utilizadores. Além disso, ela denuncia a presença de rios, lagos, áreas com lençóis freáticos mais próximos da superfície e ambientes propícios para atividades econômicas específicas.

Por fim, o usuário especialista compreenderá o objeto a ser representado no mapa como um conjunto de fatores e elementos, cuja exploração se dá indefinidamente, dependendo do nível de conhecimento exploratório aplicado ao mapa. Assim, os signos escolhidos deverão permitir sobreposições de diversas variáveis, caso o objetivo do autor de mapas seja atender a demanda de um público mais especialista que busque a visualização geográfica.

Para o público não especialista, os fenômenos deverão ser analisados da forma mais próxima pelo qual se revela ao usuário comum. Dessa forma, deve-se saber como a topografia é concebida no imaginário do grande público. Considerando-se que o modelo do relevo é percebido como um elemento da paisagem sobre o qual a sociedade se desenvolve, as feições mais comuns são aquelas que não dependem de altos graus de complexidade e abstração para sua análise. As relações topológicas entre o ser humano e seu meio são desenvolvidas pela ação dos diversos órgãos, especialmente os olhos, que realizam varreduras horizontais e verticais apresentando o fenômeno em uma perspectiva que não é adotada nas cartas topográficas (a vertical).

Algumas pesquisas, como as de Prado (2007), revelaram que a representação da topografia em modelos tridimensionais facilita o trabalho mental do leitor para a concepção do ambiente apresentado. Assim, elementos como sombras poderão ser 
adicionados à representação para reforçar os pontos mais altos presentes na topografia, facilitando, desta forma, interpretações minimamente comuns entre os leitores, como mostra a Figura 3.

Figura 3 - Soluções distintas sobre um mesmo problema.
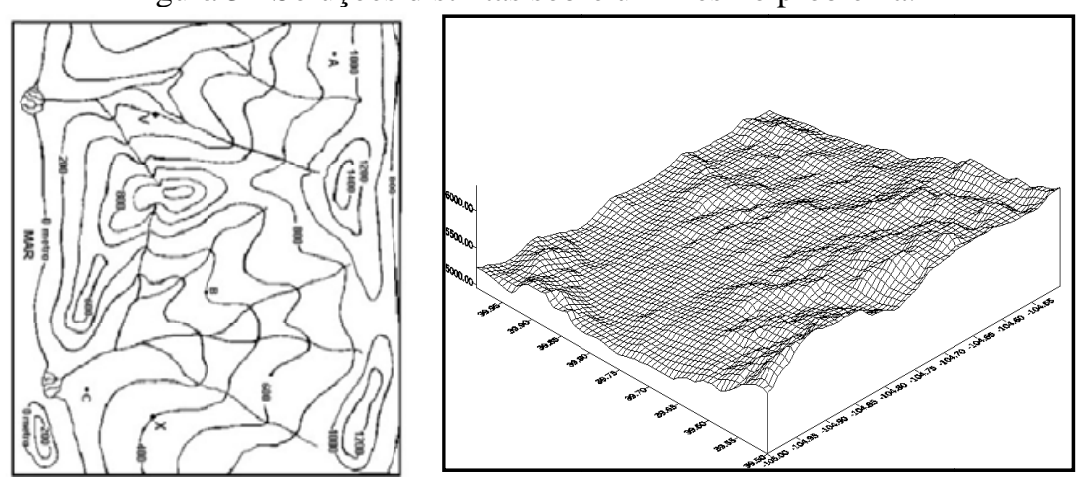

Dada a complexidade do objetivo a ser alcançado, a representação do relevo apresentou grandes variações ao longo da história. Hoje, como aponta Gaspar (2005, p.172), utiliza-se de, principalmente, três recursos: os sombreamentos, as curvas de nível e as cores hipsométricas. Esses recursos podem ser conjugados ou utilizados isoladamente, dependendo das necessidades de seus usuários.

Na busca dese representar fenômenos passíveis da ação exploratória, conferida pela visualização, as soluções deverão ser compatíveis com a natureza do signo adotado, ou seja, devem permitir ao usuário uma leitura de uma série de elementos que serão sobrepostos da forma mais harmônica possível.

Portanto, se considerarmos a topografia como resultado de uma série de fatores cientificamente comprovados e compartilhados por aqueles que comungam um mesmo código, o símbolo, referente à concepção semiótica da relação entre o representamen e o objeto na categoria da terceiridade, pode ser a solução que melhor combina as variáveis envolvidas no fenômeno.

É o símbolo, por meio das curvas de nível, que torna possível quantificar adequadamente os valores altimétricos e a configuração do espaço cartografado, ao contrário das outras duas soluções apontadas.

Para o público não especialista, a aproximação da representação do relevo em sua perspectiva de duas dimensões e meia facilita a compreensão daquilo que se pretende representar. Entretanto, nota-se que para se buscar uma relação mais icônica entre o representamen e o objeto, sacrificam-se as possíveis associações com outros elementos, condição esta necessária para o exercício da exploração e confirmação na visualização cartográfica. Se o principal objetivo do cartógrafo, por exemplo, for demonstrar que uma determinada região turística é montanhosa, talvez não seja necessário apontar os valores exatos das altitudes. Assim, as representações 
que utilizam aspectos mais figurativos da paisagem, livres de serem altamente fidedignos ao fato, podem ser uma solução mais adequada para o público não especialista. Estas condições são também existentes em mapas temáticos.

Nos mapas sinóticos confeccionados pela Marinha do Brasil, por exemplo, encontram-se soluções muito semelhantes, do ponto de vista semiótico, para a comunicação efetiva do produto cartográfico aos usuários especializados, como mostra a Figura 4.

Figura 4 - À esquerda, carta sinótica utilizada pelo público especialista. À direita, adaptação das informações voltadas ao grande público. Fonte: Sítio da Marinha do Brasil e Climatempo (2012).

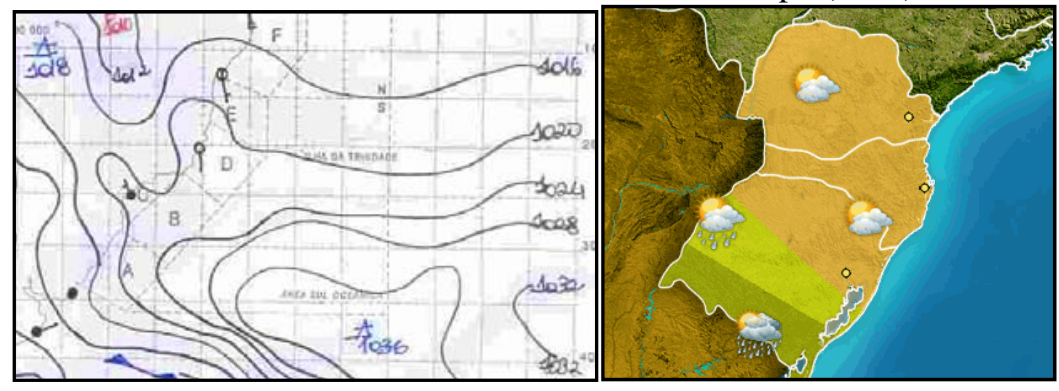

O objetivo da carta sinótica é representar a condição momentânea da atmosfera em um determinado espaço. Mas, apesar da condição da atmosfera ser comum a quaisquer indivíduos que estejam localizados no domínio privado, as potencialidades assumidas para a exploração variam de acordo com os saberes internalizados pelos observadores.

Assim como o público especializado sobre a compreensão da topografia, a atmosfera não é vista como um objeto unitário, mas a soma de diversas condições distintas. É pelo acesso ao código, nesse caso, o conhecimento científico da influência da pressão, temperatura, direção dos ventos e outros, que os especialistas comungam um mesmo saber na leitura do fenômeno, tornando-o possível de ser lido de maneira semelhante a quaisquer indivíduos que têm acesso a esse mesmo código (GARBIN et al., 2011).

Por se tratar de relações nem sempre visíveis, é necessário representar alguns fatores e elementos abstratos para a dimensão concreta de um observador comum. A solução encontrada pelo grupo de especialistas também foi possível graças à utilização de símbolos. Entretanto, para que a comunicação fosse viabilizada ao público não especializado, as informações foram sintetizadas em aspectos mais visíveis e recorrentes ao dia a dia do observador.

Ao se considerar apenas os aspectos perceptíveis do clima, a solução mais adequada para transmitir a condição momentânea da atmosfera foi através de signos de caráter icônico. Buscou-se aproximar as informações mais relevantes para a 
maioria da população (temperatura e pluviosidade) das formas mais simples possíveis.

A utilização da variação do valor de cor (tom azul) para relacionar o oceano com a representação, além da adoção de signos pictoriais que remetem a sol encoberto e chuva em áreas mais claras ou nebulosas, é o exemplo visível deste vínculo. Em um primeiro momento, o observador compreende que o signo gráfico de sol entre nuvens (objeto imediato) remete à concepção de dia provavelmente nublado, com possíveis pancadas de chuva (objeto dinâmico). Pela delimitação das condições de possível chuva e pluviosidade por meio das cores, a associação entre cor escura e tempo nublado transmite a informação de que em sua cidade a chuva chegará.

Mas as relações icônicas são muito mais escassas na carta sinótica da Marinha. Isso se dá pela necessidade de valorizar não somente um objeto - ou a chuva, ou o vento, ou o mar agitado -, mas o sistema presente, utilizado para fins e interesses variáveis para o segundo grupo.

\section{CONSIDERAÇÕES FINAIS}

$\mathrm{Na}$ tentativa de diálogo entre diversos autores e teorias que envolvem processos inerentes à leitura de mapas, este trabalho traçou algumas das variáveis que devem ser consideradas pelo autor de mapas na elaboração do projeto cartográfico, principalmente nos signos gráficos.

Sob a perspectiva de Peirce, aliada a teoria da visualização cartográfica, podese apontar que a concepção de Bertin para a criação de um produto cartográfico universal é impraticável, especialmente quando se considera os quatro distintos usos possíveis em um mapa e as particularidades dos usuários para sua interpretação.

Assim, as considerações de Slocum (1999) e Sluter (2008), sobre o processo de elaboração do projeto cartográfico se iniciar a partir do objetivo proposto pelo mapa e seu possível grupo de usuários, são válidas, sobretudo ao projeto de seus signos.

Como explicitado através da semiótica peirceana, a análise de como o fenômeno a ser cartografado se revela ao usuário pode ajudar em sua representação. Não obstante, foi apontada uma relação direta entre a utilização de ícones para o entendimento da informação espacial pelo grupo não especialista de usuários e de símbolos para os especialistas. Essa discrepância pode ser explicada pela forma com que os fenômenos são interpretados pelos dois grupos, um necessitando de dimensões mais amplas para a compreensão do processo quese estuda, e o outro, uma visão mais generalista (KULHAVY e STOCK, 1996).

Seria um erro, entretanto, indicar que os critérios para a construção semântica do símbolo não mereça quaisquer cuidados, por depender de um acordo prévio entre o autor e o seu leitor. Apesar da liberdade do símbolo em representar quaisquer tipos de fenômenos, deve-se buscar a facilitação da relação entre o representamen e o objeto sempre que possível, para que sua leitura seja facilitada e promova um rápido entendimento (KEATES 1982, p.66-67). Para tanto, nota-se que mesmo nas 
cartas topográficas e nas cartas sinóticas é buscada uma facilitação na leitura dos signos: os cursos d'água são confeccionados em cor azul no primeiro modelo, e a frente fria e quente das cartas sinóticas são azuis e vermelhas, respectivamente.

Portanto, o que se pode concluir é que o princípio que deve guiar o cartógrafo é que cada produto deve ser concebido em condições específicas, com usos definidos e público conhecido, tendo em mente as particularidades de cada grupo de usuários em realizar a leitura do conceito de realidade cartografado, e a semiótica pode auxiliar na tomada destas decisões.

\section{REFERÊNCIAS BIBLIOGRÁFICAS}

BERTIN, J. Theory of communication and theory of the graphic. In: International Yearbook of Cartography, vol.18 p.118-126, 1978.

BERTIN, J. Semiology of graphics. Translated William J. Berg. London: The University of Wisconsin Press Ltd., 1983.

BROWN, R. How shall a thing be called? In Psychological Review, vol. 65, n.1, 1958.

BRASIL, Marinha do. Carta de pressão ao nível do mar. Em: <http:// www.mar.mil.br/dhn/chm/meteo/prev/cartas/cartas.html>. Acessado em: 17 de abril de 2012.

CLIMATEMPO. Previsão diária. Disponível em: <http://www.climatempo.com.br/ mapas/>. Acessado em: 17 de abril de 2012.

GASPAR, J. A. Cartas e projeções cartográficas. Lisboa: Editora Lidel, 2005.

GARBIN, E. P.; SANTIL, F. L. P.; SILVEIRA, H. Análise da percepção das variáveis visuais de acordo com a categorização das feições das cartas sinóticas. RBC-Revista Brasileira de Cartografia (Online), v. 63, p. 427- 438, 2011.

KEATES, J. Understanding maps. London: Longman, 1982.

KULHAVY, R. W.; STOCK, W. A. How cognitive maps are leamed and remembered. Annals of the Association of American Geographers, 86(1), 123145, 1996.

LAKOFF, G. Women, Fire, and Dangerous Things: What Categories Reveal about the Mind [S. I.]: Chicago: The University of Chicago Press, 1987.

LURIA, A. R. Cognitive development: Its cultural and social foundations. Cambridge, MA: Harvard University Press, 1976.

MACEACHREN, A. M. How maps work: representation, visualization, and design. New York: The Guilford Press, 1995.

MACEACHREN, A. M. Visualization in modern cartography: setting the agenda. In: MacEachren, A. M.; Taylor, D.R.F. (Eds.) Visualization in modern cartography. Oxford: Elsevier, 1994a, p. 1-12.

MACEACHREN, A. M. Some truth with maps: a primor on symbolization and design. Washington: AAG, 1994b. 
MENDONÇA, A. L. A.; DELAZARI, L. S. Remote evaluation of the execution of spatial analysis tasks with interactive web maps: A functional and quantitative approach. Cartographic Journal, v. 49, p. 7-20, 2012.

NIVALLA, A. M. Usability Perspectives for the Design of Interactive Maps. Department of Computer Science and Engineering. Helsinki University of Technology. Finlândia, 2007. PhD tese.

NÖTH, W. Panorama da semiótica: de Platão à Peirce. São Paulo: Annablume, 2003.

PASCHOALE, C. Geologia como semiótica da natureza. São Paulo: Programa de Estudos Pós-graduados em Comunicação e Semiótica - PUC, 1989 (Tese de doutoramento).

PRADO, J. P. B. Aplicação da visualização cartográfica 3D na fase de planejamento do levantamento de solos: uma abordagem à cognição espacial. Curitiba: PPGCG/UFPR, 2007. Dissertação (Mestrado).

QUEIROZ, D. R. E. A semiologia e a cartografia temática. In: Boletim de Geografia, v. 18, n.1, p.121-127, 2000.

ROSCH, E. Cognitive Representations of Semantic Categories. Journal of Experimental Psycology, v. 104, p. 192-233, 1975.

ROSCH, E. Natural categories. Cognitive Psychology, San Diego, n. 4, p. 328350, 1973

SANTAELLA, L. O que é semiótica. São Paulo: Brasiliense, 1983.

SANTAELLA, L. Semiótica aplicada. São Paulo: Thomson, 2004.

SANTIL, F. L. P. Análise da percepção das variáveis visuais de acordo com as leis da Gestalt para representação cartográfica. Curitiba: DGEO/UFPR, 2008. (Tese de doutoramento).

SLOCUM, T. A. Thematic Cartography and Visualization. New Jersey: PrenticeHall, 1999.

SLUTER, C. R. Uma abordagem sistêmica para o desenvolvimento do projeto cartográfico como parte do processo de comunicação cartográfica. In: Portal da Cartografia, vol.1 n.1, p.1-20, 2008.

TAYLOR, D. R. F. Geographic information systems. The microcomputer and modern cartography. In: MacEachren, A. M.; Taylor, D.R.F. (Eds.) Geographic information systems: the microcomputer and modern cartography. Oxford: Elsevier, 1990. p. 1-20.

(Recebido em agosto de 2012. Aceito em novembro de 2012.) 